\title{
Food Preference of Pecky Rice Bugs Is Influenced by Experience
}

\author{
Atsuhiko Nagasawa \\ Laboratory of Insect Science and Bioregulation, Graduate School of Agricultural Science, Tohoku University, \\ Sendai, Japan \\ Email: atsu.nagasawa@gmail.com
}

Received 14 March 2016; accepted 15 April 2016; published 19 April 2016

Copyright (C) 2016 by author and Scientific Research Publishing Inc.

This work is licensed under the Creative Commons Attribution International License (CC BY). http://creativecommons.org/licenses/by/4.0/

(c) (i) Open Access

\section{Abstract}

This study investigated whether prior experience influences the plant food preference of Trigonotylus caelestialium and Stenotus rubrovittatus which cause pecky rice grain, by using rice plants and 2 poaceous weeds. In a choice experiment between Digitaria ciliaris and the rice plants, both $T$. caelestialium and $\boldsymbol{S}$. rubrovittatus adults that were reared on $\boldsymbol{D}$. ciliaris plants showed significant initial preference for $D$. ciliaris over rice. In a choice experiment between Echinochloa crus-galli var. aristata and rice plants, T. caelestialium adults reared on E. crus-galli var. aristata strongly preferred E. crus-galli var. aristata over rice throughout the experiment. However, at and after 24 $h, T$. caelestialium adults reared on rice showed no food preference, although $T$. caelestialium initially preferred $E$. crus-galli var. aristata. In contrast, $S$. rubrovittatus adults reared on rice showed no preference between $E$. crus-galli var. aristata and rice. However, $S$. rubrovittatus reared on E. crus-galli var. aristata initially preferred E. crus-galli var. aristata to rice, with this preference waning with time. The same results were obtained for both sexes. Although the effect of experience differed with food source and the species of mirid bug, prior experience initially had a noticeable effect, which disappeared with time $(1 \mathrm{~d})$.

\section{Keywords}

Trigonotylus caelestialium, Stenotus rubrovittatus, Digitaria ciliaris, Echinochloa crus-galli var. aristata, Grass Weeds

\section{Introduction}

Phytophagous insects feed on multiple plant species, whereas monophagous insects exhibit high host specificity. 
Phytophagous insect preferences are influenced by various factors, especially previous experience [1] [2]. The influence of pre- and early-adult experience on host selection has been extensively studied. Although adults are expected to prefer host species that they have been previously exposed to, both positive and negative results have been reported [3] [4]. Therefore, the effect of experience requires consideration when investigating host selection by phytophagous insects.

The rice leaf bug, Trigonotylus caelestialium (Kirkaldy), and the sorghum plant bug, Stenotus rubrovittatus (Matsumura) are major rice pests in Japan. Although the nymphs of these bugs grow well on hulled rice, rice plant leaves are not suitable food for their growth. Thus, adults are assumed to cause damage to rice grains when they move to rice plants at the heading stage after growing on other poaceous plants, along with nymphs that emerge from eggs deposited by the adults on rice. Therefore, it is important to identify host plants that are suitable for nymph growth. Field sampling and observations have identified Italian ryegrass, Lolium multiflorum; annual bluegrass, Роа апnиа; and southern crabgrass, Digitaria ciliaris as important food sources for rice bugs [5]-[7]. Laboratory tests have shown that nymphs grow well on P. annua, Alopecurus aequalis, Poasphondylodes, Hordeum murinum, Dactylis glomerata, Agrostis clavata subsp. matsumurae, L. multiflorum [8], Poa pratensis, and Digitaria violascens [9]. These plants may facilitate the development of rice bugs. Alternatively, the relative preference of rice bugs between host plants and rice plants may contribute to the occurrence of pecky rice, because rice grain damage is caused by rice bugs that move from poaceous weeds to rice plants.

It has been reported that rice leaf bugs and sorghum plant bugs are attracted to plants at specific developmental stages [10] [11]. Furthermore, rice leaf bugs prefer flowering poaceous weeds over rice plants before heading, whereas they show equal preference for flowering poaceous weeds and rice plants at the heading stage [12]. Therefore, the increase in bug populations in rice paddies after heading [5] [6] [13] is attributable to an increase in their relative preference for rice plants over other host plants. Differences in the relative preference may affect bug movement between plants. Thus, in addition to the increased effects of poaceous weeds, the relative difference in bug preference between weeds and rice plants must be considered when evaluating how plants affect the occurrence of pecky rice. Moreover, if rice bugs develop a preference for rice plants after experiencing poaceous weeds, these weeds may have a pronounced effect on the incidence of pecky rice.

To study whether bug development on poaceous weeds influences their preference for rice plants, the relative preference between poaceous weeds and rice plants was investigated for T. caelestialium and S. rubrovittatus adults that had had prior experience on different plants. In this study, Digitaria ciliaris and Echinochloa crusgalli var. aristata were used as poaceous weeds because the ears of these plants emerge during the same season as those of rice plants, and because rice bugs grow relatively better on these plants than on other poaceous weeds that are present during the season [8].

\section{Materials and Methods}

\subsection{Insects}

Trigonotylus caelestialium and Stenotus rubrovittatus were collected from fields at the Hokuriku Research Center, National Agricultural Research Center, Niigata Prefecture, Japan. These insects had been reared on young wheat seedlings under laboratory conditions $\left(16: 8 \mathrm{~L}: \mathrm{D}\right.$ photoperiod, $\left.25^{\circ} \mathrm{C}\right)$ for several years as described previously [14]-[16].

\subsection{Plants}

Digitaria ciliaris and Echinochloa crus-galli var. aristata that were growing wild, and rice, Oryza sativa, that was cultivated in the paddy fields, were collected from the fields at the Hokuriku Research Center. The flowering stages of these plants were used for tests.

\subsection{Experience Treatment}

Within $24 \mathrm{~h}$ of emergence, 50 - $150 \mathrm{~T}$. caelestialium or S. rubrovittatus adults were released in a plastic rearing cage $(34 \times 25 \times 34 \mathrm{~cm})$. Digitaria ciliaris, E. crus-galli var. aristata, and rice with flowering ears were placed in conical flasks $(100 \mathrm{ml})$ filled with water. Each plant was made available to the adults for $4 \mathrm{~d}$. The plants were renewed daily or every other day. This treatment was conducted under laboratory conditions (16:8 L:D photoperiod, $25^{\circ} \mathrm{C}$ ). 


\subsection{Choice Preference Test}

One ear each of $D$. ciliaris, E. crus-galli var. aristata, and rice was placed in sample tubes filled with water. Two tubes with $D$. ciliaris and rice or $E$. crus-galli var. aristata and rice were placed diagonally at the corner of a plastic rearing cage $(34 \times 25 \times 34 \mathrm{~cm})$. Ten adults reared on these plants as described above were released in a plastic cup (top diameter: $8 \mathrm{~cm}$, bottom diameter: $6 \mathrm{~cm}$, height: $4 \mathrm{~cm}$ ). The plastic cup was placed at the center of the plastic rearing cage and then the cap was removed to allow the adults to disperse. Adults reared on $D$. ciliaris were released in D. ciliaris vs. rice cages. Those on E. crus-galli var. aristata were released in E. crusgalli var. aristata vs. rice cages. Those on rice were released in $D$. ciliaris vs. rice cages or $E$. crus-galli var. aristata vs. rice cages. The number of adults on the plants was counted at 3, 6, 24, 27, and $30 \mathrm{~h}$ after starting the test. The test was conducted separately for males and females to prevent interaction between the sexes from influencing food preference. Twelve cages (i.e., 120 individuals) were used for each test, except for T. caelestialium males reared on E. crus-galli var. aristata (7 cages). These tests were conducted under rearing conditions (16:8 L:D photoperiod, $25^{\circ} \mathrm{C}$ ).

\subsection{Statistical Analysis}

The numbers of adults on rice plants and other poaceous plants were compared at each time point using binomial test. The ratios of the adults present on the plant species on which they had been reared versus those present on the plant species on which they had not been reared were compared between rice and each poaceous species at each time point using Fisher's exact test. For example, at $3 \mathrm{~h}$, the total number of $T$. caelestialium females reared on $D$. ciliaris that were present on $D$. ciliaris and rice was 64 and 25 individuals, respectively (Figure 1(a)). At the same time period, the total number of $T$. caelestialium females reared on rice that were present on D. ciliaris and rice was 44 and 41 individuals, respectively (Figure 1(b)). These two ratios (64/25 and 44/41) were then compared statistically by Fisher's exact test. If these ratios were significantly different, prior food experience probably influenced bug preference.

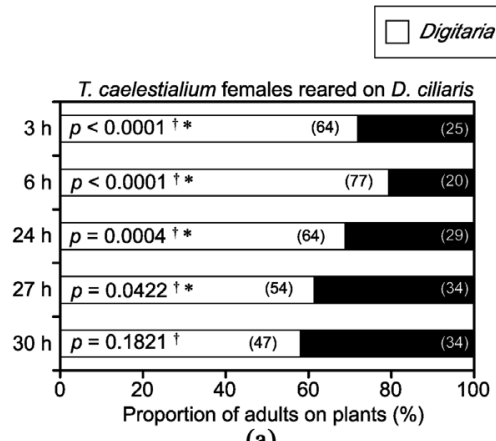

(a)

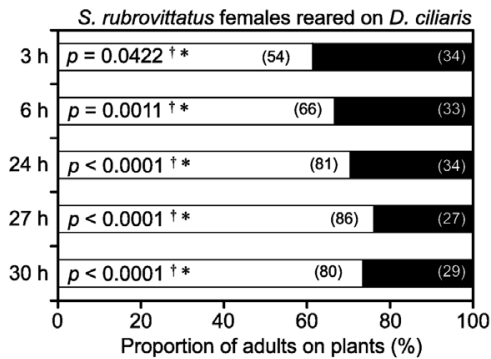

(c)

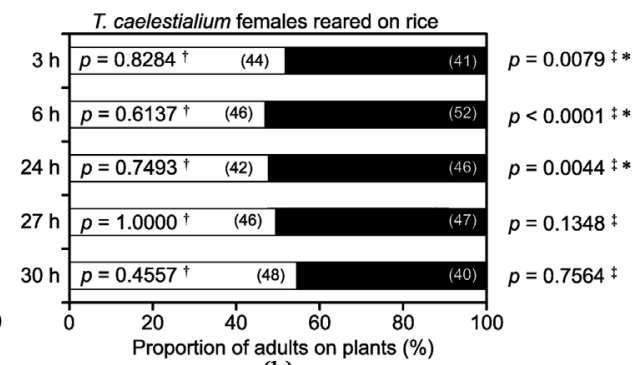

(b)

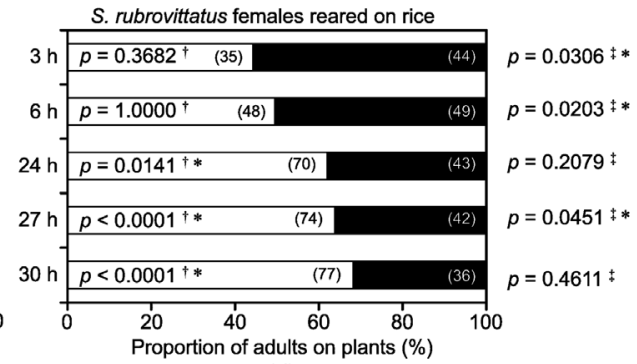

(d)

Figure 1. Proportion of adult rice bug females on Digitaria ciliaris versus those on rice plants. Choice preference tests between $D$. ciliaris and rice were conducted with a: Trigonotylus caelestialium reared on $D$. ciliaris, b: $T$. caelestialium reared on rice, c: Stenotus rubrovittatus reared on D. ciliaris, and d: S. rubrovittatus reared on rice. The adults were counted at 3, 6 , 24,27 , and $30 \mathrm{~h}$. The numbers in parentheses represent the number of adults on plants. ${ }^{\dagger}: \mathrm{P}$ values comparing the number of adults on $D$. ciliaris and that on rice at each time point using binomial test. ${ }^{\ddagger}$ : P values comparing the proportion of adults present on $D$. ciliaris and rice (i.e., the plants used for rearing) at the same time points using Fisher's exact test. Asterisk $\left({ }^{*}\right)$ represents $p<0.05$. 


\section{Results}

\subsection{Choice Preference Test between Digitaria ciliaris and Rice}

\subsubsection{Trigonotylus caelestialium}

After rearing of females on $D$. ciliaris, a significantly higher number of females was found on $D$. ciliaris than on rice at 3, 6, 24, and $27 \mathrm{~h}$ (number of individuals on $D$. ciliaris/rice $=64 / 25,77 / 20,64 / 29$, and 54/34 respectively) (binomial test, $p<0.05$; Figure 1(a)); however, after $30 \mathrm{~h}$, there was no significant difference in the number of females on $D$. ciliaris and rice (number of individuals on $D$. ciliaris/rice $=47 / 34$ ) (binomial test, $p>0.05$; Figure 1(a)). In contrast, after rearing of females on rice, the number of females present on rice was not significantly different between $D$. ciliaris and rice (number of individuals on $D$. ciliaris/rice at $3,6,24,27$, and $30 \mathrm{~h}=$ 44/41, 46/52, 42/46, 46/47, and 48/40 respectively) (binomial test, $p>0.05$; Figure 1(b)). The ratio of females present on the two tested plants used for rearing (D. ciliaris and rice) was significantly different at 3,6 , and $24 \mathrm{~h}$ (Fisher's exact test, $p<0.05$; Figure 1(a) and Figure 1(b)), whereas no significant difference was observed at 27 and 30 h (Fisher's exact test, $p>0.05$; Figure 1(a) and Figure 1(b)).

After rearing of males on $D$. ciliaris, a significantly higher number of adult males was present on $D$. ciliaris than on rice at 3, 6, and $27 \mathrm{~h}$ (number of individuals on $D$. ciliaris/rice $=46 / 27,64 / 15$, and 42/22 respectively) (binomial test, $p<0.05$; Figure 2(a)), with no significant difference in male ratios at all other time points (number of individuals on $D$. ciliaris/rice at 24 and $30 \mathrm{~h}=35 / 27$ and 38/25 respectively) (binomial test, $p>0.05$; Figure 2(a)). However, the number of males reared on rice was not significantly different between $D$. ciliaris and rice at all of the time points (number of individuals on $D$. ciliaris/rice at 3, 6, 24, 27, and $30 \mathrm{~h}=39 / 37$, 34/39, 24/26, 28/25, and 29/27 respectively) (binomial test, $p>0.05$; Figure 2(b)). The ratio of males present on the two tested plants used for rearing (D. ciliaris and rice) was significantly different at $6 \mathrm{~h}$ (Fisher's exact test, $p<0.05$; Figure 2(a) and Figure 2(b)), but not at any of the other time points (Fisher's exact test, $p>0.05$; Figure 2(a) and Figure 2(b)).

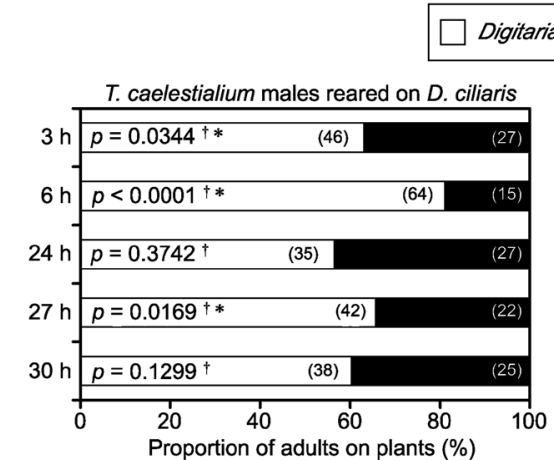

(a)

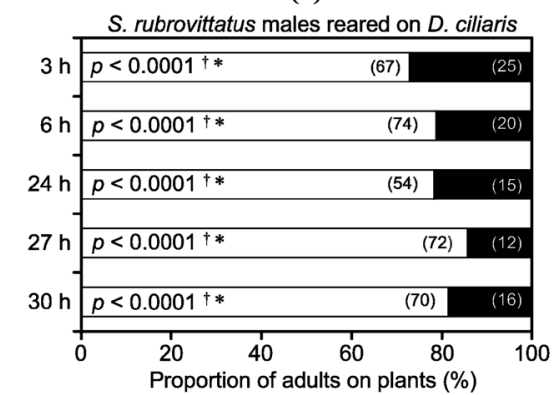

(c)

ria ciliaris $\square$ Rice

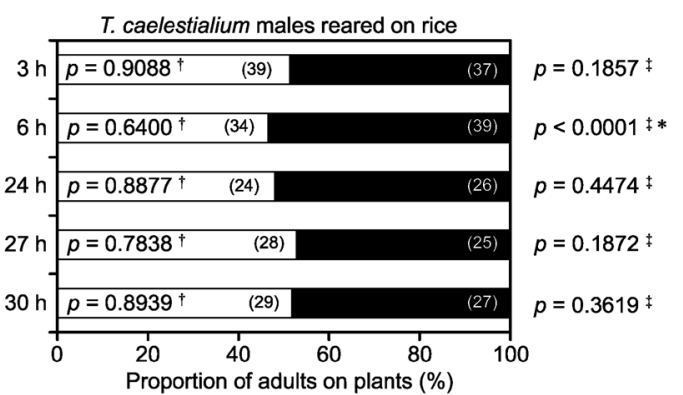

(b)

$S$. rubrovittatus males reared on rice

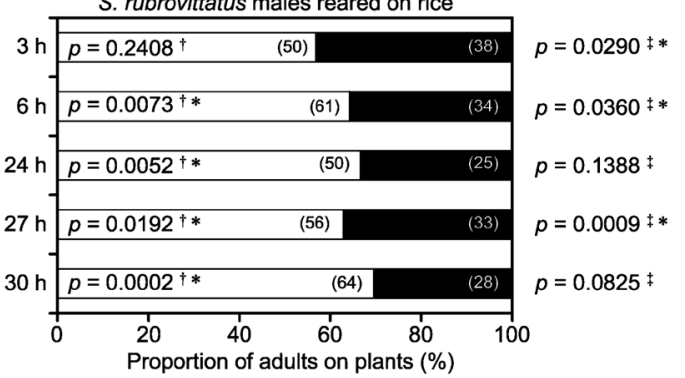

(d)

Figure 2. Proportion of adult rice bug males on Digitaria ciliaris versus those on rice plants. Choice preference tests between $D$. ciliaris and rice were conducted with (a): Trigonotylus caelestialium reared on D. ciliaris; (b): T. caelestialium reared on rice; (c): Stenotus rubrovittatus reared on D. ciliaris, and (d): S. rubrovittatus reared on rice. The adults were counted at 3, 6, 24, 27, and $30 \mathrm{~h}$. The numbers in parentheses represent the number of adults on plants. ${ }^{\dagger}: \mathrm{P}$ values comparing the number of adults on $D$. ciliaris and that on rice at each time point using binomial test. ${ }^{\ddagger}$ : $\mathrm{P}$ values comparing the proportion of adults present on $D$. ciliaris and rice (i.e., the plants used for rearing) at the same time points using Fisher's exact test. Asterisk $\left(^{*}\right)$ represents $p<0.05$. 


\subsubsection{Stenotus rubrovittatus}

After rearing of females on $D$. ciliaris, a significantly higher number of females was present on $D$. ciliaris versus rice at all of the time points (number of individuals on $D$. ciliaris/rice at 3, 6, 24, 27, and $30 \mathrm{~h}=54 / 34,66 / 33$, 81/34, 86/27, and 80/29 respectively) (binomial test, $p<0.05$; Figure 1(c)). After rearing of females on rice, there was no significant difference in the number of adult females on rice and D. ciliaris at 3 and $6 \mathrm{~h}$ (number of individuals on $D$. ciliaris/rice $=35 / 44$ and $48 / 49$ respectively) (binomial test, $p>0.05$; Figure 1 (d)); however, a significantly higher number of females was present on $D$. ciliaris than on rice at $24 \mathrm{~h}$ and later (number of individuals on $D$. ciliaris/rice at 24,27 , and $30 \mathrm{~h}=70 / 43,74 / 42$, and 77/36 respectively) (binomial test, $p<0.05$; Figure 1(d). The ratio of females present on the two tested plants used for rearing (D. ciliaris and rice) was significantly different at 3, 6, and $27 \mathrm{~h}$ (Fisher's exact test, $p<0.05$; Figure 1(c) and Figure 1(d)), but not at 24 and $30 \mathrm{~h}$ (Fisher's exact test, $p>0.05$; Figure 1(c) and Figure 1(d)).

After rearing of males on $D$. ciliaris, a significantly higher number of males was present on $D$. ciliaris than on rice at all of the time points (number of individuals on $D$. ciliaris/rice at 3, 6, 24, 27, and $30 \mathrm{~h}=67 / 25,74 / 20$, $54 / 15,72 / 12$, and 70/16 respectively) (binomial test, $p<0.05$; Figure 2(c)). After rearing of males on rice, no significant difference in the number of males was detected between $D$. ciliaris and rice at $3 \mathrm{~h}$ (number of individuals on $D$. ciliaris/rice $=50 / 38$ ) (binomial test, $p>0.05$; Figure $2(\mathrm{~d})$ ); however, a significantly higher number of males was present on $D$. ciliaris at $6 \mathrm{~h}$ and after (number of individuals on $D$. ciliaris/rice at 6, 24, 27, and $30 \mathrm{~h}=61 / 34,50 / 25,56 / 33$, and 64/28 respectively) (binomial test, $p<0.05$; Figure 2(d)). The ratio of males present on the two plants used for rearing (D. ciliaris and rice) was significantly different at 3,6 , and $27 \mathrm{~h}$ (Fisher's exact test, $p<0.05$; Figure 2(c) and Figure 2(d)), but not at 24 and $30 \mathrm{~h}$ (Fisher's exact test, $p>0.05$; Figure 2(c) and Figure 2(d)).

\subsection{Choice Preference Test between E. crus-galli var. aristata and Rice}

\subsubsection{Trigonotylus caelestialium}

After rearing of females on $E$. crus-galli var. aristata, a significantly higher number of females was present on $E$. crus-galli var. aristatathan on rice at all of the time points (number of individuals on E. crus-galli var. aristata/rice at 3, 6, 24, 27, and $30 \mathrm{~h}=71 / 8,58 / 8,47 / 8,41 / 1$, and 42/10 respectively) (binomial test, $p<0.05$; Figure $3(a))$. In contrast, after rearing of females on rice, a significantly higher number of females was present on $E$. crus-galli var. aristata than on rice at 3 and $6 \mathrm{~h}$ (number of individuals on E. crus-galli var. aristata/rice $=73 / 16$ and 74/23 respectively) (binomial test, $p<0.05$; Figure 3(b)), with no significant difference being documented at $24 \mathrm{~h}$ and after (number of individuals on E. crus-galli var. aristata/rice at 24, 27, and $30 \mathrm{~h}=49 / 34,38 / 33$, and 30/34 respectively) (binomial test, $p>0.05$; Figure 3(b)). The ratio of females present on the plants used for rearing (E. crus-galli var. aristata and rice) was significantly different at 24 - $30 \mathrm{~h}$ (Fisher's exact test, $p<0.05$; Figure 3(a) and Figure 3(b)), but not at 3 and 6 h (Fisher's exact test, $p>0.05$; Figure 3(a) and Figure 3(b)).

After rearing of males on E. crus-galli var. aristata, a significantly higher number of males was present on $E$. crus-gallivar. aristata than on rice at 3 - $27 \mathrm{~h}$ (number of individuals on E. crus-gallivar. aristata/rice at 3, 6, 24, and $27 \mathrm{~h}=28 / 8,30 / 6,17 / 1$, and 21/4 respectively) (binomial test, $p<0.05$; Figure 4(a)), whereas there was no significant difference at $30 \mathrm{~h}$ (number of individuals on E. crus-galli var. aristata/rice $=16 / 3$ ) (binomial test, $p>$ 0.05; Figure 4(a)). In contrast, after rearing of males on rice, a significantly higher number of males was present on E. crus-galli var. aristata than on rice at 3 and $6 \mathrm{~h}$ (number of individuals on E. crus-galli var. aristata/rice = 60/15 and 58/12 respectively) (binomial test, $p<0.05$; Figure 4(b)), whereas no significant difference was detected at $24 \mathrm{~h}$ or later (number of individuals on E. crus-galli var. aristata/rice at 24, 27, and $30 \mathrm{~h}=40 / 24,37 / 21$, and 39/17 respectively) (binomial test, $p>0.05$; Figure 4(b)). The ratio of males present on the plants used for rearing (E. crus-galli var. aristata or rice) was significantly different at $24 \mathrm{~h}$ (Fisher's exact test, $p<0.05$; Figure 4(a) and Figure 4(b)), but not at any other time point (Fisher's exact test, $p>0.05$; Figure 4(a) and Figure $4(\mathrm{~b}))$.

\subsubsection{Stenotus rubrovittatus}

After rearing of females on $E$. crus-galli var. aristata, a significantly higher number of females was present on $E$. crus-galli var. aristata than on rice at 3 and $6 \mathrm{~h}$ (number of individuals on E. crus-galli var. aristata/rice $=60 / 13$ and 70/17 respectively) (binomial test, $p<0.05$; Figure 3(c)), whereas there was no significant difference at 24 $\mathrm{h}$ or later (number of individuals on E. crus-galli var. aristata/rice at 24, 27, and $30 \mathrm{~h}=46 / 60,43 / 57$, and 47/50 


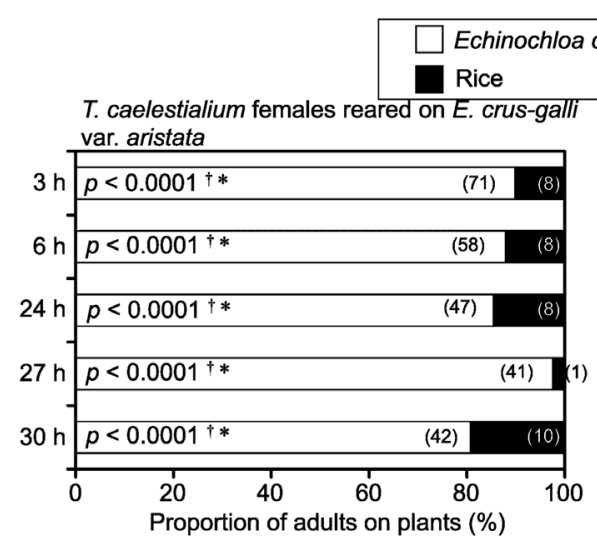

(a)

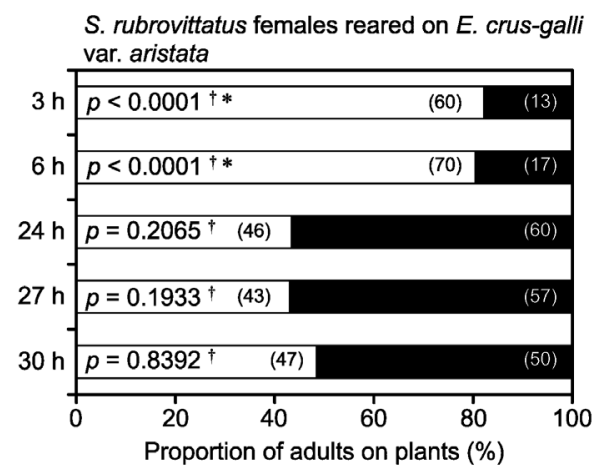

(c)

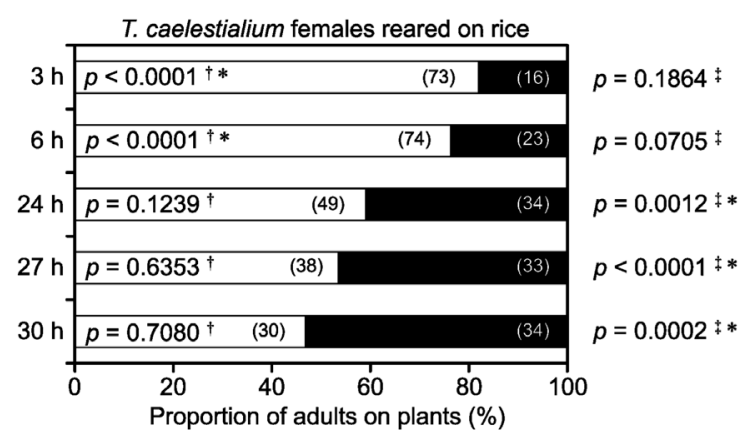

(b)

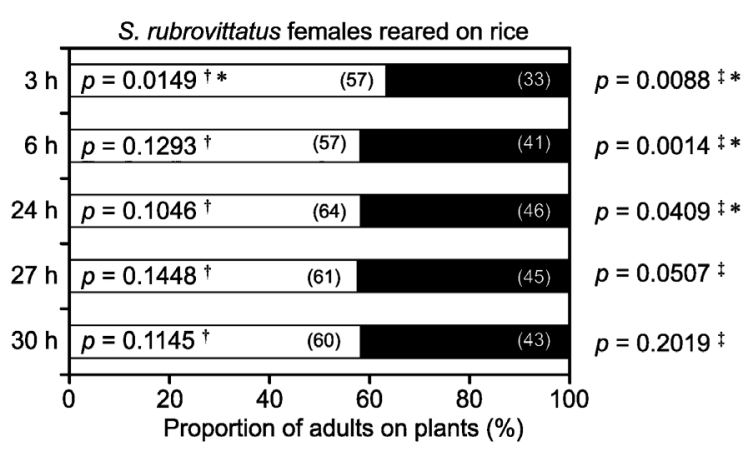

(d)

Figure 3. Proportion of adult rice bug females on Echinochloa crus-galli var. aristata versus those on rice plants. Choice preference tests between E. crus-galli var. aristata and rice were conducted with (a): Trigonotylus caelestialium reared on E. crus-galli var. aristata; (b): T. caelestialium reared on rice; (c): Stenotus rubrovittatus reared on E. crus-galli var. aristata, and (d): S. rubrovittatus reared on rice. The adults were counted at 3, 6, 24, 27, and $30 \mathrm{~h} .^{\dagger}$ : P values comparing the number of adults on E. crus-galli var. aristata and that on rice at each time point using binomial test. The numbers in parentheses represent the number of adults on plants. ${ }^{\ddagger}$ : P values comparing the proportion of adults present on E. crus-galli var. aristata and rice (i.e., plants used for rearing) at the same time points using Fisher's exact test. Asterisk $\left(^{*}\right)$ represents $p<0.05$.

respectively) (binomial test, $p>0.05$; Figure 3(c)). In contrast, after rearing of females on rice, a slightly higher number of females was present on E. crus-galli var. aristata than on rice at $3 \mathrm{~h}$ (number of individuals on $E$. crus-galli var. aristata/rice $=57 / 33$ ) (binomial test, $p<0.05$; Figure 3(d)), whereas no significant difference in the number of females was observed at 6 h or later (number of individuals on E. crus-galli var. aristata/rice at 6 , 24, 27, and $30 \mathrm{~h}=57 / 41,64 / 46,61 / 45$, and 60/43 respectively) (binomial test, $p>0.05$; Figure 3(d)). The ratio of females present on the plants used for rearing (E. crus-galli var. aristata and rice) was significantly different at 3, 6, and 24 h (Fisher's exact test, $p<0.05$; Figure 3(c) and Figure 3(d)), but not at 27 h or later (Fisher's exact test, $p>0.05$; Figure 3(c) and Figure 3(d)).

After rearing males on E. crus-galli var. aristata, a significantly higher number of males was present on $E$. crus-galli var. aristata than on rice at 3 and 6 h (number of individuals on E. crus-galli var. aristata/rice = 76/15 and 74/13 respectively) (binomial test, $p<0.05$; Figure 4(c)), whereas no significant difference was detected at $24 \mathrm{~h}$ or later (number of individuals on E. crus-galli var. aristata/rice at 24, 27, and $30 \mathrm{~h}=38 / 29$, 46/24, and 42/34 respectively) (binomial test, $p>0.05$; Figure $4(\mathrm{c})$ ). In contrast, after rearing of males on rice, there was no significant difference in the number of males present on E. crus-galli var. aristataor rice at any of the time points (number of individuals on E. crus-galli var. aristata/rice at 3, 6, 24, 27, and $30 \mathrm{~h}=40 / 35$, 55/42, 30/38, 30/48, and 31/47 respectively) (binomial test, $p>0.05$; Figure $4(d)$ ). The ratio of males present on the plants used for rearing (E. crus-galli var. aristata and rice) was significantly different at 3, 6, and 27 h (Fisher's exact test, $p<0.05$; Figure 4(c) and Figure 4(d)), but not at 24 and 30 h (Fisher's exact test, $p>0.05$; Figure 4(c) and Figure 4(d)). 


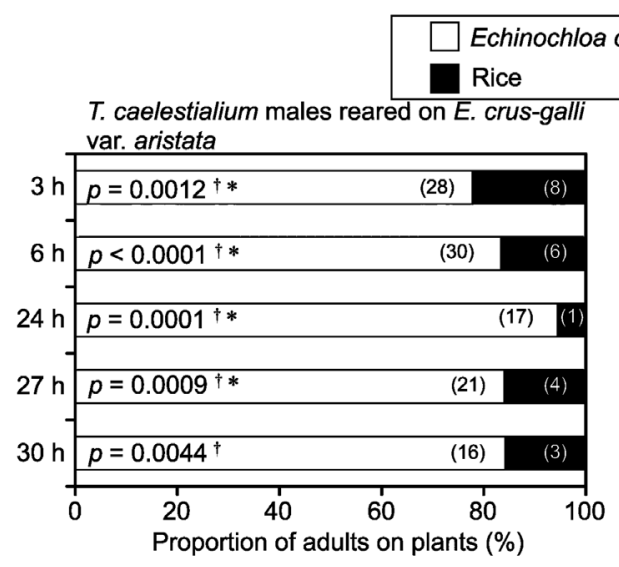

(a)

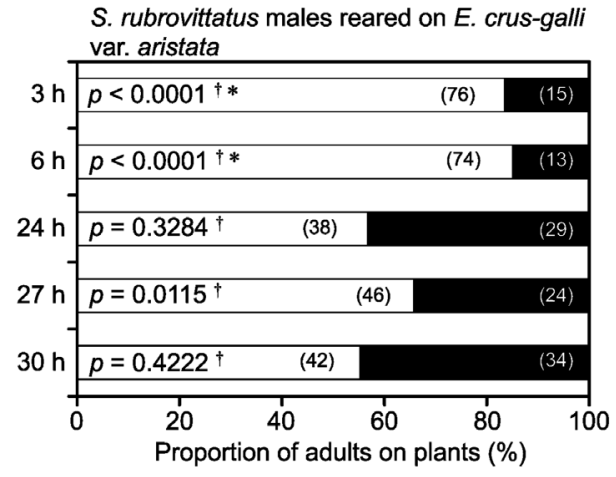

(c)

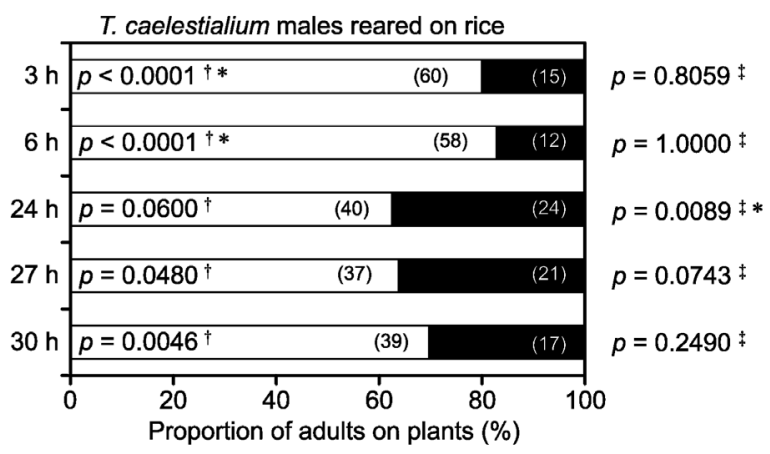

(b)

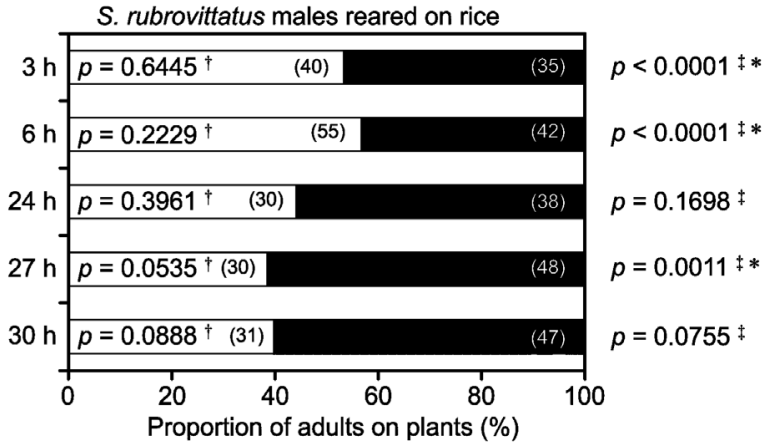

(d)

Figure 4. Proportion of adult rice bug males on Echinochloa crus-galli var. aristata versus those on rice plants. Choice preference tests between $E$. crus-galli var. aristata and rice were conducted with (a): Trigonotylus caelestialium reared on E. crus-galli var. aristata; (b): T. caelestialium reared on rice; (c): Stenotus rubrovittatus reared on E. crus-galli var. aristata, and (d): S. rubrovittatus reared on rice. The adults were counted at 3, 6, 24, 27, and $30 \mathrm{~h} .^{\dagger}:$ : values comparing the number of adults on E. crus-galli var. aristata and that on rice at each time point using binomial test. The numbers in parentheses represent the number of adults on plants. ${ }^{\ddagger}$ : P values comparing the proportion of adults present on E. crus-galli var. aristata and rice (i.e., plants used for rearing) at the same time points using Fisher's exact test. Asterisk ( ${ }^{*}$ ) represents $p<0.05$.

\section{Discussion}

Stenotus rubrovittatus exhibited different preferences for the two tested poaceous plants $(D$. ciliaris and $E$. crus-galli var. aristata) versus rice. In the $D$. ciliaris-rice combination, after rearing of individuals on $D$. ciliaris, more $S$. rubrovittatus adults preferred $D$. ciliaris to rice. In contrast, after rearing of individuals on rice, no preference between rice and $D$. ciliaris was initially detected, although more adults frequented $D$. ciliaris over time (about $1 \mathrm{~d}$ ). In contrast, for the E. crus-galli var. aristata-rice combination, after rearing of $S$. rubrovittatus on rice, adults exhibited no preference between $E$. crus-galli var. aristata and rice at any of the time points (except females at $3 \mathrm{~h}$ ). However, after rearing of individuals on E. crus-galli var. aristata, more adults initially preferred E. crus-galli var. aristata over rice. This observation contrasted with the results obtained for $D$. ciliaris, wherein the difference between $D$. ciliaris and rice disappeared with time. Significant differences in the ratios were initially obtained between plants used for rearing for both the $D$. ciliaris-rice combination and the $E$. crusgalli var. aristata-rice combination, with this difference disappearing over time (about $1 \mathrm{~d}$ ). These results indicate that rearing plant experience influenced food preference initially, but this effect disappeared over time (about $1 \mathrm{~d}$ ). Variation in the preference of rice bugs for rice and the two weed species (D. ciliaris and $E$. crusgalli var. aristata) may thus be influenced by innate preferences.

The ratio of the number of $S$. rubrovittatus adults on $D$. ciliaris versus rice and $E$. crus-galli var. aristata versus rice increased with time, possibly because $S$. rubrovittatus had a stronger preference for $D$. ciliaris than for $E$. crus-galli var. aristata. In comparison, the ratio of $T$. caelestialium adult numbers on $D$. ciliaris versus rice de- 
creased with time, whereas it remained consistently higher for E. crus-galli var. aristata versus rice, possibly because $T$. caelestialium has a stronger preference for $E$. crus-galli var. aristata than for $D$. ciliaris. If prior experience affects preference, after rearing of $T$. caelestialium adults on rice, more individuals would be expected to prefer rice over E. crus-galli var. aristata initially, and then this preference would subsequently decrease. However, the opposite results were obtained. It is possible that the quality of plants in the flasks deteriorated with time. Nevertheless, preference should be influenced by prior experience, because significantly different adult ratios were obtained between the two weeds and rice, depending on the plants used for rearing. Because $T$. caelestialium had a strong preference for E. crus-galli var. aristata, adults reared on E. crus-galli var. aristata might have retained this preference, even when the test plants deteriorated. In contrast, $T$. caelestialium adults reared on rice might have selected E. crus-galli var. aristata when the plants were in good condition, switching to rice plants when $E$. crus-galli var. aristata deteriorated.

Prior experience influenced plant preference behavior of $T$. caelestialium and $S$. rubrovittatus. However, the effect of experience disappeared after just $1 \mathrm{~d}$. Experience during specific periods (egg-young larvae) has been shown to influence adult oviposition in a parasitic wasp [17]. In contrast, oviposition by Drosophila melanogaster is influenced by odor exposure immediately before testing, with this effect being enhanced by the length of the exposure period [18]. Thus, $4 \mathrm{~d}$ might have been a too short duration for the rice bugs to have gained sufficient experience in this study. Alternatively, $1 \mathrm{~d}$ of experience might be sufficient, and rice bugs might experience and adjust to other plants (i.e., the non-rearing plant) during the tests. Thus, further study is required to understand the relationship between the length of experience and the strength of the effect of experience.

It remains unclear what regulates the relationship between preference and prior experience. Both rice bug species are attracted by odors released from host plants [10]-[12] [19]. Attraction behavior is altered by olfactory learning in several phytophagous insects [20]-[24]. Therefore, these bugs may be influenced by learning plant odors. However, because the current experiment was conducted in a narrow cage, plant selection by the bugs was probably not caused by their attraction to volatile compounds; rather, they probably remained on the plant following direct contact or sucking (feeding).

Trigonotylus caelestialium and S. rubrovittatus females release sex attractants to attract males [25]-[28]. However, it remains unclear how attractants influence the behavior of bugs in narrow cages; thus, the males and females are separated in the selection test to avoid any interaction between sexes. The results showed that both sexes exhibited the same preference trends; thus, differences between the sexes were not considered in this study.

In the current study, adult bugs tended to select plants that they had previously experienced. If the effect of experience in nymphs is sustained to the adult stage, adults may select the same plant species as that on which the nymphs grew. Therefore, if these two rice bug species developed on weeds, they would probably select the same plant species as adults. However, if the weeds deteriorate and disappear, the bugs may transfer and adjust to rice plants in a relatively short period. The results of this study showed that the influence of prior experience declined with time, leading to a situation where the adult ratio on rice plants versus weeds became equal. Thus, these ratios indicate innate preference. Consequently, even though rice bugs grow on weeds, they are expected to adjust to rice plants with time, and spread over rice paddies.

In this study, it was expected that the mirid bugs that developed on poaceous weeds would be inhibited from moving to rice plants because of the effect of food experience, leading to food preference. Although the food preferences of the bugs were influenced by prior experience, this effect was unlikely to be strong. The adult mirid bugs changed their preference for rice plants in a short time period $(1 \mathrm{~d})$. In this study, only 2 species of poaceous weeds were used for the tests; however, the two bugs showed different responses to these weeds. Hence, it is important to investigate the effect of other plants. Previous studies have already demonstrated how the oviposition [29] and nymphal growth [8] of these bugs on poaceous weeds may influence the extent to which they may damage rice. However, the factors that influence the relative preference of these bugs for weeds over rice must also be determined, because these bugs develop on poaceous weeds in the vicinity of paddy fields, after which the adults transfer to rice plants. This information would be valuable for understanding how weeds influence rice damage by mirid bugs.

\section{Acknowledgements}

I am grateful to Dr. H. Higuchi, Ryukoku University, and Dr. A. Takahashi, NARO Tohoku Agricultural Research Center, for their support and suggestions. 


\section{References}

[1] Bernays, E.A. and Chapman, R.F. (1994) Host-Plant Selection by Phytophagous Insects. Chapman \& Hall, New York. http://dx.doi.org/10.1007/b102508

[2] Schoonhoven, L.M., van Loon, J.J.A. and Dicke, M. (2005) Insect-Plant Biology. 2nd Edition, Oxford University Press, Oxford.

[3] Barron, A.B. (2001) The Life and Death of Hopkins’ Host-Selection Principle. Journal of Insect Behavior, 14, 725737. http://dx.doi.org/10.1023/A:1013033332535

[4] Szentesi, Á. and Jermy, T. (1990) The Role of Experience in Host Plant Choice by Phytophagous Insects. In: Bernays, E.A., Ed., Insect-Plant Interactions, CRC Press, Boca Raton, 39-74.

[5] Hayashi, H. (1986) Ecology and Control of the Sorghum Plant Bug (Stenotus rubrovittatus Matsumura) Causing the Pecky Rice. Plant Protection, 40, 321-326.

[6] Hayashi, H. and Nakazawa, K. (1988) Studies on the Bionomics and Control of the Sorghum Plant bug, Stenotus rubrovittatus Matsumura (Hemiptera: Miridae) 1. Habitat and Seasonal Prevalence in Hiroshima Prefecture. Bulletin of the Hiroshima Prefectural Agricultural Experiment Station, 51, 45-53.

[7] Hachiya, K. (1999) Migration of Rice Leaf Bug, Trigonotylus caelestialium (Kirkaldy) into Rice Fields and Forecasting of the Abundance. Plant Protection, 53, 268-272.

[8] Nagasawa, A. and Higuchi, H. (2012) Suitability of Poaceous Plants for Nymphal Growth of the Pecky Rice Bugs Trigonotylus caelestialium and Stenotus rubrovittatus (Hemiptera: Miridae) in Niigata, Japan. Applied Entomology and Zoology, 47, 421-427. http://dx.doi.org/10.1007/s13355-012-0135-5

[9] Kikuchi, A. and Kobayashi, T. (2004) Growth and Oviposition of the Rice Leaf Bug, Trigonotylus caelestialium (Kirkaldy) (Heteroptera: Miridae), on Gramineous Weeds and Italian Rye Grass. Annual Report of the Society of Plant Protection of North Japan, 55, 149-154.

[10] Niiyama, T., Fujii, T., Hori, M. and Matsuda, K. (2007) Olfactory Response of Trigonotylus caelestialium (Het.: Miridae) to Rice Plant and Gramineous Weeds. Journal of Applied Entomology, 131, 513-517. http://dx.doi.org/10.1111/j.1439-0418.2007.01161.x

[11] Hori, M. (2009) Olfactory Response of Stenotus rubrovittatus to Rice and Paddy Weed, Scirpus juncoides. Journal of Applied Entomology, 133, 438-443. http://dx.doi.org/10.1111/j.1439-0418.2009.01398.x

[12] Fujii, T., Hori, M. and Matsuda, K. (2010) Influence of Host Plant Odours on Invasion of the Rice Leaf Bug Trigonotylus caelestialium into Paddy Fields. Agricultural and Forest Entomology, 12, 99-105. http://dx.doi.org/10.1111/j.1461-9563.2009.00457.x

[13] Ishimoto, M. (2004) Seasonal Prevalence of Occurrence of the Rice Leaf Bug, Trigonotylus caelestialium (Kirkaldy) (Heteroptera: Miridae) on Paddy Rice Plants. Japanese Journal of Applied Entomology and Zoology, 48, 79-85. http://dx.doi.org/10.1303/jjaez.2004.79

[14] Nagasawa, A. and Higuchi, H. (2008) A Method for Rearing Stenotus rubrovittatus (Matsumura) (Heteroptera: Miridae) by Using the Spikelets of Gramineous Weeds as Oviposition Sites and Wheat Seedlings for Rearing Nymphs. Japanese Journal of Applied Entomology and Zoology, 52, 1-6. http://dx.doi.org/10.1303/jiaez.2008.1

[15] Higuchi, H. and Takahashi, A. (2000) Method of Rearing the Rice Leaf Bug, Trigonotylus caelestialium (Kirkaldy) (Heteroptera: Miridae) with Wheat Seedlings. Proceedings of the Association for Plant Protection of Hokuriku, 48, 23-25.

[16] Nagasawa, A. and Higuchi, H. (2010) Storage of Stem Cuttings of Wheat Seedlings under High-Humidity Conditions to Improve Larval Emergence after Oviposition by Stenotus rubrovittatus (Matsumura) (Heteroptera: Miridae). Japanese Journal of Applied Entomology and Zoology, 54, 197-203. http://dx.doi.org/10.1303/jjaez.2010.197

[17] Gandolfi, M., Mattiacci, L. and Dorn, S. (2003) Preimaginal Learning Determines Adult Response to Chemical Stimuli in a Parasitic Wasp. Proceedings of the Royal Society of London, Series B, 270, 2623-2629. http://dx.doi.org/10.1098/rspb.2003.2541

[18] Barron, A.B. and Corbet, S.A. (2000) Behavioural Induction in Drosophila: Timing and Specificity. Entomologia Experimentalis et Applicata, 94, 159-171. http://dx.doi.org/10.1046/j.1570-7458.2000.00616.x

[19] Fujii, T., Hori, M. and Matsuda, K. (2010) Attractants for Rice Leaf Bug, Trigonotylus caelestialium (Kirkaldy), Are Emitted from Flowering Rice Panicles. Journal of Chemical Ecology, 36, 999-1005. http://dx.doi.org/10.1007/s10886-010-9839-6

[20] Carlsson, M.A., Anderson, P., Hartlieb, E. and Hansson, B.S. (1999) Experience-Dependent Modificaion of Orientational Response to Olfactory Cues in Larvae of Spodoptera littoralis. Journal of Chemical Ecology, 25, 2445-2454. http://dx.doi.org/10.1023/A:1020865922827 
[21] Radžiutè, S. and Būda, V. (2013) Host Feeding Experience Affects Host Plant Odour Preference of the Polyphagous Leafminer Liriomyza bryoniae. Entomologia Experimentalis et Applicata, 146, 286-292. http://dx.doi.org/10.1111/eea.12028

[22] Wang, H., Guo, W.F., Zhang, P.J., Wu, Z.Y. and Liu, S.S. (2008) Experience-Induced Habituation and Preference towards Non-Host Plant Odors in Ovipositing Females of a Moth. Journal of Chemical Ecology, 34, 330-338. http://dx.doi.org/10.1007/s10886-008-9433-3

[23] Cunningham, J.P., Moore, C.J., Zalucki, M.P. and West, S.A. (2004) Learning, Odour Preference and Flower Foraging in Moths. Journal of Experimental Biology, 207, 87-94. http://dx.doi.org/10.1242/jeb.00733

[24] Landolt, P.J. (2001) Moth Experience and Not Plant Injury Affected Female Cabbage Looper Moth (Lepidoptera: Noctuidae) Orientation to Potato Plants. Florida Entomologist, 84, 243-249. http://dx.doi.org/10.2307/3496174

[25] Kakizaki, M. and Sugie, H. (1997) Attraction of Males to Females in the Rice Leaf Bug, Trigonotylus caelestialium. Applied Entomology and Zoology, 32, 648-651.

[26] Kakizaki, M. and Sugie, H. (2001) Identification of Female Sex Pheromone of the Rice Leaf Bug, Trigonotylus caelestialium. Journal of Chemical Ecology, 27, 2447-2458. http://dx.doi.org/10.1023/A:1013623414324

[27] Okutani-Akamatsu, Y., Watanabe, T. and Azuma, M. (2007) Mating Attraction by Stenotus rubrovittatus (Heteroptera: Miridae) Females and Its Relationship to Ovarian Development. Journal of Economic Entomology, 100, 1276-1281. http://dx.doi.org/10.1603/0022-0493(2007)100[1276:MABSRH]2.0.CO;2

[28] Yasuda, T., Shigehisa, S., Yuasa, K., Okutani-Akamatsu, Y., Teramoto, N., Watanabe, T. and Mochizuki, F. (2008) Sex Attractant Pheromone of the Sorghum Plant Bug Stenotus rubrovittatus (Matsumura) (Heteroptera: Miridae). Applied Entomology and Zoology, 43, 219-226. http://dx.doi.org/10.1303/aez.2008.219

[29] Nagasawa, A., Takahashi, A. and Higuchi, H. (2012) Host Plant Use for Oviposition by Trigonotylus caelestialium (Hemiptera: Miridae) and Stenotus rubrovittatus (Hemiptera: Miridae). Applied Entomology and Zoology, 47, 331-339. http://dx.doi.org/10.1007/s13355-012-0123-9 